\title{
Predicting preterm labour by cervical length measurement
}

\section{Preeti Priyadarshani*, Gurcharan Kaur}

\author{
${ }^{1}$ Department of Obstetrics and Gynaecology, Mahatma Gandhi Institute of Medical Science, Wardha, Maharashtra, \\ India \\ ${ }^{2}$ Department of Obstetrics and Gynaecology, Kasturba Hospital, New Delhi, India
}

Received: 27 February 2016

Revised: 19 April 2016

Accepted: 07 May 2016

\author{
*Correspondence: \\ Dr. Preeti Priyadarshani, \\ E-mail: drpreeti.priyadarshani@yahoo.in
}

Copyright: () the author(s), publisher and licensee Medip Academy. This is an open-access article distributed under the terms of the Creative Commons Attribution Non-Commercial License, which permits unrestricted non-commercial use, distribution, and reproduction in any medium, provided the original work is properly cited.

\begin{abstract}
Background: This study was undertaken to ascertain the role of cervical length measurement by Transvaginal Ultrasonography as a predictor for preterm labour.

Methods: Routine Antenatal cases presenting to the O.P.D. of Obstetrics and Gynaecology at 18-24 weeks of gestation were enrolled and subjected to transvaginal ultrasound for measurement of cervical length. The STUDY group consisted of 50 patients with cervical length being $</=25 \mathrm{~mm}$. The CONRTOL group consisted of 50 patients with cervical length being $>25 \mathrm{~mm}$. Patients were followed up to observe the outcome of their pregnancies. The data was analyzed using SPSS version 15.0 software.

Results: The positive predictive value of cervical length $</=25 \mathrm{~mm}$ was $6 \%, 16 \%, 30 \%$ and $50 \%$ for delivery before $28,32,34$ and 37 weeks respectively; the negative predictive value for the same was $100 \%, 100 \%, 98 \%$ and $86 \%$. A cervical length of $<25 \mathrm{~mm}$ at the initial sonographic examination was associated with a relative risk (RR) of 15 for spontaneous preterm birth before 34 weeks and 3.75 for spontaneous preterm birth before 37 weeks. Maternal outcome was comparable in the study and control groups. However, the babies born in the study group had greater morbidities associated with prematurity, lower birth weight, higher NICU admission rates, longer duration of NICU stay and greater mortality rates as compared to the babies born in the control group.

Conclusions: Measurement of cervical length aids in early detection of patients who are likely to go into preterm labour and identification of high-risk group.
\end{abstract}

Keywords: Transvaginal sonography, Cervical length, Preterm labour

\section{INTRODUCTION}

"Being born too soon is an unrecognized killer".

Joy Lawn ${ }^{1}$

Preterm birth is the leading cause of neonatal morbidity and mortality, and its prevention is an important healthcare priority. ${ }^{2}$ Despite advances in perinatal care, the incidence of preterm birth continues to rise. ${ }^{3-5}$ The prevention of preterm labour remains a major challenge in contemporary obstetrics. ${ }^{6,7}$ Identification of patients who are at an increased risk for preterm labour requires the use of diagnostic tools that can be applied to both asymptomatic and symptomatic pregnant women. Current methods of identifying women at increased risk of preterm delivery involve analysing a combination of factors such as obstetric history and demographic features as well as assessment of uterine contractions, biochemical markers and evaluation of the cervix. ${ }^{8-11}$

Ultrasonic assessment of uterine cervix has emerged as an alternative method to assess cervical length and morphology, and thus establish the risk of developing preterm labour. 
This study was undertaken to ascertain the role of cervical length measurement by Transvaginal Ultrasonography as a predictor for preterm labour.

\section{METHODS}

A prospective analysis was conducted at the department of Obstetrics and Gynaecology, Kasturba Hospital in the year 2013-2014. Routine Antenatal cases presenting to the OPD of Obstetrics and Gynaecology at 18-24 weeks of gestation were enrolled in the study. A detailed history and examination was done and an informed written consent was taken. These patients were subjected to transvaginal ultrasound for measurement of cervical length. Cervical length was measured from the internal os to the external os along the endocervical canal. The shortest of three consecutive readings was noted.

After measuring cervical length by transvaginal sonography, the patients were divided into two groups: 50 patients with cervical length $<25 \mathrm{~mm}$ were placed in study group and 50 patients with cervical length $>25 \mathrm{~mm}$ were taken as controls.

All the patients included in the study were followed up in routine antenatal O.P.D. and their maternal and foetal outcome was noted. Patients detected with a cervical length $<15 \mathrm{~mm}$ were admitted and treated as per hospital protocol.

The data collected during the study was analysed using Statistical Package for Social Sciences (SPSS) version 15.0 software. Quantitative variables were compared between the two groups using unpaired t-test. Qualitative variables were compared using the Chi-square/Fisher's exact test.

\section{RESULTS}

The mean cervical length as measured by transvaginal sonography in the study group was $21.56 \mathrm{~mm}$ (SD 4.07). The minimum length measured was $9 \mathrm{~mm}$ and the maximum length measured was $25 \mathrm{~mm}$ in the study group.

The mean cervical length as measured by transvaginal sonography in the control group was $38.00 \mathrm{~mm}$ (SD8.23). The minimum length measured was $26 \mathrm{~mm}$ and the maximum length measured was $60 \mathrm{~mm}$ in the control group. The difference in mean cervical length between the two groups was statistically significant, with a pvalue of $<0.001$.

Five patients $(10 \%)$ in the study group required admission to the hospital in the antenatal period for management of very short cervical length $(<15 \mathrm{~mm})$.

In the study group, 25 out of $50(50 \%)$ patients delivered before completing 37 weeks of gestation whereas in the control group, only 7 out of $50(14 \%)$ patients delivered before completing 37 weeks of gestation.

The mean gestational age at delivery was 35.44 weeks (SD 3.90) in the study group. The mean gestational age at delivery was 38.17 weeks (SD 1.51) in the control group. The p-value was $<0.001$, making the difference between the two groups highly significant.

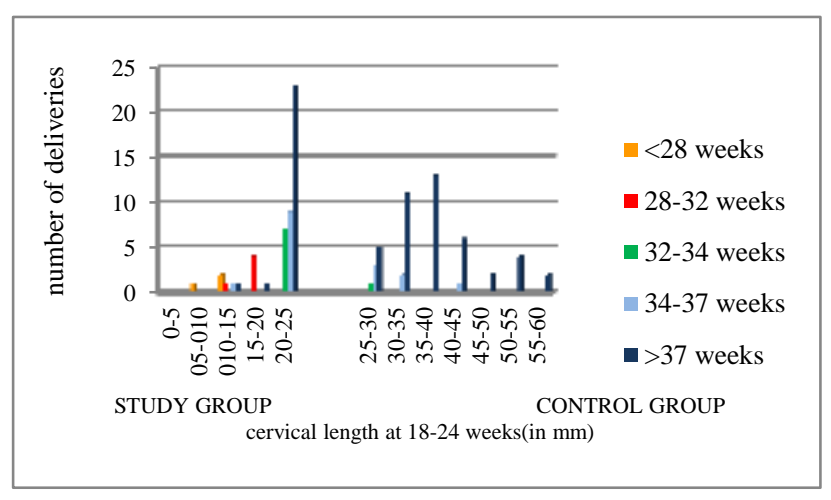

Figure 1: Period of gestation at delivery according to cervical length.

The patients in the two groups were comparable for the duration of labour and mode of delivery and gave birth to live babies with comparable APGAR scores.

The mean birth weight in the study group was $2.23 \mathrm{~kg}$ (SD 0.71); and in the control group was $2.72 \mathrm{~kg}$ (SD $0.31)$. The p-value was $<0.001$, making the difference in the two groups highly significant. The minimum birth weight was $530 \mathrm{gms}$ and $2.1 \mathrm{kgs}$ in the study and control groups respectively.

A total of 20 out of 50 babies (40\%) in the study group required admission to the NICU, of which four babies died during their stay in the NICU. Only 3out of 50 babies $(6 \%)$ in the control group required admission to the NICU, all of them were healthy at the time of discharge from the hospital. The difference in NICU admissions between the two groups was statistically significant.

The indications for admission of babies to the NICU in the study group were respiratory distress at birth (12 cases, 60\%), low birth weight $<1.5 \mathrm{~kg}$ ( 8 cases, $40 \%$ ), Meconium Aspiration Syndrome (3 cases, 15\%) and hyperbilirubinemia ( 2 cases, 10\%). Five babies were admitted with more than one indication for admission. During their stay in the NICU, eight out of twelve babies with respiratory distress were identified as Respiratory Distress Syndrome, three babies (15\%) developed Necrotising Enterocolitis and three babies (15\%) developed sepsis. All four babies who died during NICU stay were born with extremely low birth weight and developed respiratory distress syndrome. 
Of the three babies admitted to the NICU in the control group, two were for meconium aspiration syndrome and one was for sepsis. No baby was admitted with more than one indication for admission and no mortality was reported.

The difference in neonatal morbidities due to respiratory distress syndrome, necrotising enterocolitis and low birth weight was statistically significant between the study and control groups, with p-value $<0.05$.

The mothers and the rest of the babies in the study and control group had an uneventful follow-up at one month post-delivery of baby.

\section{DISCUSSION}

A statistically significant inverse relationship between mid- trimester cervical length on transvaginal sonography and the subsequent risk of preterm birth has been observed in our study.

Table 1: Predictive value of cervical length $<25 \mathrm{~mm}$.

\begin{tabular}{|llll|}
\hline POG at delivery & PPV & NPV & RR \\
\hline$<28$ weeks & 6 & 100 & - \\
\hline$<32$ weeks & 16 & 100 & - \\
\hline$<34$ weeks & 30 & 98 & 15 \\
\hline$<37$ weeks & 50 & 86 & 3.57 \\
\hline
\end{tabular}

For predicting preterm birth before 28 weeks, the positive predictive value of cervical length $<25 \mathrm{~mm}$ was $16 \%$ and negative predictive value of cervical length $<25 \mathrm{~mm}$ was $100 \%$.

For predicting preterm birth before 32 weeks, the positive predictive value and negative predictive value of cervical length $<25 \mathrm{~mm}$ was $16 \%$ and $100 \%$ respectively.

For predicting preterm birth before 34 weeks, the positive predictive value and negative predictive value of cervical length $<25 \mathrm{~mm}$ was $30 \%$ and $98 \%$ respectively.

For predicting preterm birth before 37 weeks, the positive predictive value and negative predictive value of cervical length $<25 \mathrm{~mm}$ was $50 \%$ and $86 \%$ respectively.

A cervical length of $<25 \mathrm{~mm}$ at the initial sonographic examination was associated with a relative risk (RR) for spontaneous preterm birth before 34 weeks of 15 (95\% confidence interval [CI], 3.74-60.22).

A cervical length of $<25 \mathrm{~mm}$ at the initial sonographic examination was associated with a relative risk (RR) for spontaneous preterm birth before 37 weeks of 3.57 (95\% confidence interval [CI], 1.87-6.81).

There was no observable difference in the maternal outcome in the study and control groups. However, the babies born in the study group had greater morbidities associated with prematurity, lower birth weight, higher NICU admission rates, longer duration of NICU stay and greater mortality rates as compared to the babies born in the control group.

Table 2: Comparison of predictive value and relative risk of various studies over time.

\begin{tabular}{|c|c|c|c|c|c|c|c|c|}
\hline Study & Year & $\begin{array}{l}\text { Sample } \\
\text { size }\end{array}$ & $\begin{array}{l}\text { POG at } \\
\text { TVS }\end{array}$ & $\begin{array}{l}\text { Cervical } \\
\text { length } \\
\text { cut-off }\end{array}$ & $\begin{array}{l}\text { POG } \\
\text { cut-off }\end{array}$ & PPV & NPV & $\mathbf{R} \mathbf{R}$ \\
\hline Iams et al & 1996 & 2915 & 24 & $25 \mathrm{~mm}$ & 35 weeks & 18 & 97 & 6.19 \\
\hline \multirow{6}{*}{ Hibbard et al } & \multirow{6}{*}{2000} & \multirow{6}{*}{760} & \multirow{6}{*}{$16-22.6$} & \multirow{3}{*}{$27 \mathrm{~mm}$} & 37weeks & \multirow{6}{*}{$\begin{array}{l}\text { Range } \\
15-47\end{array}$} & \multirow{6}{*}{$\begin{array}{l}\text { Range } \\
80-98\end{array}$} & 5.4 \\
\hline & & & & & 35weeks & & & 7.5 \\
\hline & & & & & 32weeks & & & 9.7 \\
\hline & & & & \multirow{3}{*}{$22 \mathrm{~mm}$} & 37weeks & & & 6.3 \\
\hline & & & & & 35weeks & & & 7.8 \\
\hline & & & & & 32weeks & & & 8.4 \\
\hline Owen et al & 2001 & 183 & $16-22.6$ & $25 \mathrm{~mm}$ & 35weeks & 55 & - & 4.5 \\
\hline \multirow{2}{*}{ Fukami et al } & \multirow{2}{*}{2003} & \multirow{2}{*}{3030} & \multirow{2}{*}{$16-19$} & \multirow{2}{*}{$30 \mathrm{~mm}$} & 32weeks & 8.3 & 99.9 & _ \\
\hline & & & & & $32-36$ & 33.3 & 97.6 & _- \\
\hline Hebbar et al & 2006 & 200 & $20-24$ & $25 \mathrm{~mm}$ & 37weeks & 56 & 98 & - \\
\hline Rashed et al & 2009 & 294 & $20-24$ & $27.5 \mathrm{~mm}$ & 37weeks & 100 & 86 & _- \\
\hline \multirow{3}{*}{ Barber et al } & \multirow{3}{*}{2010} & \multirow{3}{*}{2351} & \multirow{3}{*}{$18-22$} & $28 \mathrm{~mm}$ & \multirow{3}{*}{ 37weeks } & 63.6 & 93.5 & _ \\
\hline & & & & $29 \mathrm{~mm}$ & & 51 & 94 & _- \\
\hline & & & & $30 \mathrm{~mm}$ & & 31 & 94 & _- \\
\hline \multirow{4}{*}{ Present Study } & \multirow{4}{*}{2014} & \multirow{4}{*}{$50+50$} & \multirow{4}{*}{$18-24$} & \multirow{4}{*}{$25 \mathrm{~mm}$} & 28weeks & 6 & 100 & _- \\
\hline & & & & & 32weeks & 16 & 100 & - \\
\hline & & & & & 34weeks & 13 & 98 & 15 \\
\hline & & & & & 37weeks & 50 & 86 & 3.57 \\
\hline
\end{tabular}


Table 1 shows the predictive values and relative risks of cervical length measurement for prediction of preterm labour as measured by various studies over time. Although low positive predictive value limits the usefulness of cervical length measurement, the high negative predictive value helps avoid unnecessary interventions and can be used in screening of asymptomatic obstetric populations.

Iams et al found an inverse relation between the length of the cervix, as measured by ultrasonography during pregnancy, and the frequency of preterm delivery. ${ }^{12}$ Although the predictive value of ultrasonography was low in their low-risk study population, it was expected to rise with the risk of prematurity in the population studied.

Hibbard et al conducted a prospective observational study in 760 gravidas at $160 / 7$ to $226 / 7$ weeks. Eighty-five women delivered before 37 weeks, 51 before 35 weeks, and 27 before 32 weeks. ${ }^{13}$ Relative risks $(95 \% \mathrm{CI})$ for spontaneous preterm delivery before 37 weeks was 3.8 $(2.6,5.6)$ for the tenth percentile; RRs for before 35 weeks was $4.5(2.9,6.9)$; and for before 32 weeks was 5.2 $(3.3,8.3)$, respectively. Sensitivity ranged from $13-44 \%$, specificity $90-99 \%$, positive predictive value $15-47 \%$, and negative predictive value $80-98 \%$.

Owen et al also support that the length of the cervix is an indirect indicator of its competence and should recognise that the relationship between cervical length and spontaneous preterm births functions along a continuum. ${ }^{14}$ The high positive predictive values observed in their study can be attributed to their selection of women with a prior early spontaneous preterm birth as the study subjects.

In a large prospective study conducted by Fukami et al the overall rate of preterm delivery was $3.2 \%$ and that of 22-31 weeks' gestation was $0.3 \%$ and $32-36$ weeks' gestation was $2.9 \% .{ }^{15}$ Most $(91.7 \%)$ preterm births were after 32 weeks' gestation. For predicting preterm birth before 32 weeks' gestation, the sensitivity, specificity, PPV, and NPV of cervical length were 50\%, 98.5\%, 8.3\% and $99.9 \%$. For predicting preterm birth after 32 weeks' gestation the sensitivity, specificity, PPV, and NPV of cervical length were $18.2 \%, 98.9 \%, 33.3 \%$ and $97.6 \%$.

The study by Hebbar et al was a prospective study conducted in India involving 200 low risk singleton pregnancies. ${ }^{16}$ Even after excluding women with a cervix shorter than $20 \mathrm{~mm}$, (prophylactic circlage was done in these patients), these investigators found that when cervical length was less than $25 \mathrm{~mm}$, only $33 \%$ delivered beyond term, where as those with more than $25 \mathrm{~mm}$, $87.5 \%$ of women could achieve term delivery.

In a prospective study of women with a singleton pregnancy at 20-24 weeks, Rashed et al found that $10.8 \%$ of the women delivered prematurely. ${ }^{17}$ Transvaginal ultrasonographic cervical length measurements of term and preterm deliveries showed a statistically significant difference $(\mathrm{P}<0.05)$.

Barber et al reported their observational prospective study on the relationship between cervical length between the 18th and 22nd week of pregnancy (as weeks of amenorrhea) and pregnancy duration at delivery. ${ }^{18}$ A total of 184 deliveries $(7.2 \%)$ occurred before the 37 th week. Before the 37 th week, the odds ratios (ORs) of spontaneous delivery for cervical lengths in the 3rd, 5th, and 10th percentiles were, respectively, $25.47(95 \%$ confidence interval [CI], 15.5-41.73); 16.98 (95\% CI, 11.51-25.05); and 7.55 (95\% CI, 5.44-10.5). In predicting premature delivery, the sensitivity, specificity, PPV, and NPV of cervical length were $26 \%, 98 \%, 63.6 \%$, and $93.57 \%$ for the 3 rd percentile; $34 \%, 97 \%, 51 \%$, and $94 \%$ for the 5th percentile; and 39\%, 92\%, 31\%, and $94 \%$ for the 10 th percentile.

Universal cervical length screening has also proven to be cost effective. ${ }^{19,20}$ However, it still has not been accepted as a part of routine antenatal care. At this time, ACOG "recognizes that both sides of this debate raise valid issues" 21 and warrants further studies before a decision can be made.

\section{CONCLUSION}

The outcome of our study indicates that screening antenatal women for a short cervical length helps us recognize asymptomatic women at risk of a subsequent preterm birth. Though the incidence of preterm labour is low in the general population, it increases manifold in the presence of a concomitant short cervix. Transvaginal ultrasonography is a simple, safe, non-invasive OPD procedure for exact measurement of cervical length. The length of the cervix is found useful in predicting the risk of premature delivery, with a shorter cervix predicting a higher risk of preterm labour.

Measurement of cervical length aids in early detection of patients who are likely to go into preterm labour and identification of high-risk group. Universal cervical length screening will help prevent preterm births and reduce neonatal morbidity and mortality.

Funding: No funding sources

Conflict of interest: None declared

Ethical approval: The study was approved by the Institutional Ethics Committee

\section{REFERENCES}

1. Lawn J. Global Evidence and Policy for Save the Children's Saving Newborn Lives program and coeditor of Born Too Soon: The global action report on preterm births. World Health Organization. Geneva 2012. From: http://www.marchofdimes.com/ materials/BornTooSoonGARonPretermBirth_05212 012.pdf. 
2. Behrman RE, Butler AS (eds). Committee on Understanding Premature Birth and Assuring Healthy Outcomes, Board on Health Sciences Policy. Preterm Birth Causes, Consequences, and Prevention, Institute of Medicine of the National Academies. The National Academies Press: Washington D.C., 2007.

3. Joseph KS, Kramer MS, Wu Wen S, Alexander D. Determinants of preterm birth in Canada from 1981 through 1992, and 1992 through 1994. N Engl J Med. 1998;339:1434-9.

4. PeriStats. White Plains, NY: March of Dimes; 2006. Available from: http://www.marchofdimes.com/ peristats/ [accessed on April 2006].

5. Callaghan WM, MacDorman MF, Rasmussen SA, Qin C, Lackritz EM. The contribution of preterm birth to infant mortality rates in the United States. Pediatrics. 2006;118:1566-73.

6. McMillan JA, Feigin RD, DeAngelis C. Oski's Pediatrics: Principles \& Practice, Lippincott Williams and Wilkins. 2006;182.

7. Georgiou HM, Permezel M, Brennecke SP. Predicting Preterm Labour: Current Status and Future Prospects Dis Markers. 2015:435014. Published online 2015 Jun 15.

8. Lockwood CJ, Senyei AE, Dische MR, Casal D, Shah KD, Thung SN. Fetal fibronectin in cervical and vaginal secretions as a predictor of preterm delivery. N Engl J Med. 1991;325(10):669-74.

9. American College of Obsterticians and Gynecologists: Preterm Labour. Technical Bulletin No. 206, June 1995.

10. Hueston WJ. Preterm contractions in community settings:II. Predicting preterm birth in women with preterm contractions. Obstet Gynecol. 1998;92:43-6.

11. Macones GA, Segel SY, Stamilio DM, Morgan MA. Predicting delivery within 48 hours in women treated with parenteral tocolysis. Obstet Gynecol. 1999;93:432-6.

12. Iams JD, Goldenberg RL, Meis PJ, Mercer BM, Moawad A, Das A, et al. The length of the cervix and the risk of spontaneous premature delivery.
National Institute of Child Health and Human Development Maternal Fetal Medicine Unit Network. N Engl J Med. 1996;334:567-72.

13. Hibbard JU, Tart M, Moawad AH. Cervical length at 16-22 weeks' gestation and risk for preterm delivery. Obstet Gynecol. 2000;96(6):972-8.

14. Owen J, Yost N, Berghella V, Thom E, Swain M, Dildy GA, et al. for the National Institute for Child Health and Human Development Maternal Fetal Medicine Unit Network. Mid-trimester endovaginal sonography in women at high risk for spontaneous preterm birth. JAMA. 2001;286:1340-8.

15. Fukami T, Ishihara K, Sekiya T, Araki T. Is Transvaginal Ultrasonography at Mid-trimester Useful for Predicting Early Spontaneous Preterm Birth? J Nippon Med Sch. 2003;70(2).

16. Hebbar S, Samjhana K. Role of mid-trimester transvaginal cervical ultrasound in prediction of preterm delivery. Med J Malaysia. 2006;61(3):30711.

17. Rashed M, Rawashdeh M, Be-Kaen K. Prediction of preterm labor by ultrasonographic cervical length. RMJ. 2009;34(2):191-4.

18. Barber MA, Eguiluz I, Plasencia W, Medina M, Valle L, Garcia JA. Preterm delivery and ultrasound measurement of cervical length in Gran Canaria, Spain International Journal of Gynecology \& Obstetrics. 2010;108(1):58-60.

19. Werner EF, Han CS, Pettker CM. Universal cervicallength screening to prevent preterm birth: a costeffectiveness analysis. Ultrasound Obstet Gynecol. 2011;38:32-7.

20. Campbell S. Universal cervical-length screening and vaginal progesterone prevents early preterm births, reduces neonatal morbidity and is cost saving: doing nothing is no longer an option. Ultrasound Obstet Gynecol. 2011;38:1-9.

21. Committee on Practice Bulletins Obstetrics, The American College of Obstetricians and Gynecologists. Practice bulletin no. 130: prediction and prevention of preterm birth. Obstet Gynecol. 2012;120:964-973.

Cite this article as: Priyadarshani P, Kaur G. Predicting preterm labour by cervical length measurement. Int J Reprod Contracept Obstet Gynecol 2016;5:1809-13. 